\title{
Práticas de Cuidados e a Humanização em Saúde: uma Experiência de Estágio Curricular em Psicologia
}

\author{
Eichherr, Letícia Maísa; Cruz, Lilian Rodrigues da; Rosa, Aline Badch \\ Universidade de Santa Cruz do Sul _ le_maisa@yahoo.com.br
}

Este trabalho apresenta a experiência de Estágio Integrado em Psicologia - atividade curricular do curso de Psicologia - em um Hospital de Ensino da cidade de Santa Cruz do Sul, região central do estado do Rio Grande do Sul. o principal objetivo é refletir sobre a inserção da estagiária em diferentes unidades de cuidados em saúde a partir de diferentes práticas "psi". Além disto, propõe-se pensar a ação da psicologia em um hospital que busque a promoção de um processo de cuidado e autocuidado em saúde envolvendo e valorizando os diferentes autores deste processo - paciente, familiares, profissionais - e fomentando a autonomia, o protagonismo e a corresponsabilidade destes sujeitos. a partir das diretrizes da Política Nacional de Humanização, com destaque para a clínica ampliada, e da possibilidade de um trabalho multiprofissional e interdisciplinar com enfoque biopsicossocial, a prática de estágio busca ações que fomentem a construção de saberes, instigando a reflexão acerca dos cuidados dispensados e dos cuidados promovidos. uma das ações desenvolvidas ao longo do estágio são os grupos terapêuticos, como forma de envolver os diferentes sujeitos nas práticas de cuidado. um dos grupos é destinado aos acompanhantes de pacientes adultos internados e o outro aos pais de pacientes da Unidade de Terapia Intensiva Neopediátrica e da Unidade de Cuidados Intermediários. Ambos permitem a troca de experiências, questionamentos, reflexões e construção de saberes acerca da internação, dos sentimentos vivenciados no cotidiano hospitalar, bem como das possibilidades de autonomia no que se refere aos cuidados para com os sujeitos. o desafio da consolidação dos grupos no hospital é constante ao verificarmos a baixa adesão de pacientes e familiares, e, principalmente, dos profissionais. ao analisar esta constatação, percebe-se a dificuldade na corresponsabilização por atividades além das prescritas. Outra atividade desenvolvida são os atendimentos na beira do leito para pacientes e familiares ou acompanhantes. a problematização sobre a inclusão do outro neste caso, dos familiares - no processo de internação hospitalar é constante, pois este outro ainda é visto como incômodo por muitos profissionais. o "outro" que questiona, duvida, participa, mas que, afinal, cuida. Partilhar estas problematizações com reflexões transversalizadas pela Política Nacional de Humanização fomenta os coletivos e possibilita um olhar ampliado aos sujeitos e uma atenção integral à saúde, assim como oportuniza repensar a atividade do psicólogo no campo hospitalar, o qual por si só, já é um local com inúmeros procedimentos invasivos e não nos cabe ser mais um deles. Ressalta-se, por fim, a não busca por conclusões, mas sim interrogações permanentes sobre as práticas que envolvem os processos de saúde-doença e a autonomia dos sujeitos no que se refere à inclusão destes nos cuidados consigo e com o outro.

Eichherr, Letícia Maísa; Cruz, Lilian Rodrigues da; Rosa, Aline Badch. Práticas de Cuidados e a Humanização em Saúde: uma Experiência de Estágio Curricular em Psicologia. In: Anais do Congresso Internacional de Humanidades \& Humanização em Saúde [= Blucher Medical Proceedings, num.2, vol.1]. São Paulo: Editora Blucher, 2014. ISSN 2357-7282

DOI 10.5151/medpro-cihhs-10247 